\title{
CRESCIMENTO DE BANANEIRAS SOB DIFERENTES NÍVEIS DE SALINIDADE DA ÁGUA DE IRRIGAÇÃ̃O ${ }^{1}$
}

\author{
GILCIMAR ALVES DO CARMO², JOSÉ FRANCISMAR DE MEDEIROS ${ }^{3}$, JOSÉ CELESMÁRIO TAVARES ${ }^{3}$, HANS RAJ \\ GHEYI $^{4}$, ANA MARIA DE SOUZA ${ }^{5}$, ELBA ARAÚJO DE QUEIROZ PALÁCIO ${ }^{6}$
}

RESUMO - Avaliaram-se os efeitos do uso de diferentes níveis de salinidade da água de irrigação $\left(\mathrm{S}_{1}=0,55 \mathrm{dS} / \mathrm{m}, \mathrm{S}_{2}=1,70 \mathrm{dS} / \mathrm{m}, \mathrm{S}_{3}=2,85 \mathrm{dS} / \mathrm{m}\right.$ e $\mathrm{S}_{1}=4,00 \mathrm{dS} / \mathrm{m}$ ) no crescimento vegetativo de bananeiras Pacovan (AAB) e Marmelo (ABB), utilizando-se um solo Argissolo Crômico, textura francoargilo-arenosa e adotando-se um delineamento experimental em blocos completos casualizados, com parcelas subdivididas e quatro repetições. As parcelas experimentais foram compostas de uma fileira com 10 plantas, sendo cinco de cada cultivar, com as três plantas centrais de cada sub-parcela consideradas úteis. As irrigações foram feitas diariamente ou a cada dois dias de modo a proporcionar uma fração de lixiviação ao redor de $0,15 \%$, colocando-se volumes aproximados de água para manter o solo próximo à capacidade de campo. Os resultados obtidos aos 110, 160, 220, 300 e 360 dias após o plantio mostraram que o incremento nos níveis de salinidade diminuiu significativamente a altura da planta, o número de folhas e a área foliar com o aumento do nível de salinidade da água até no máximo 240 dias do desenvolvimento, havendo uma equiparação depois do período chuvoso.

Termos para indexação: Bananeira, salinidade, irrigação, sodicidade.

\section{GROWTH IN BANANA CULTIVARS UNDER DIFFERENT SALINITY LEVELS OF IRRIGATION WATER}

ABSTRACT - The effects of different salinity levels of irrigation water $\left(\mathrm{S}_{1}=0.55 \mathrm{dS} / \mathrm{m}, \mathrm{S}_{2}=1.70 \mathrm{dS} / \mathrm{m}, \mathrm{S}_{3}=2.85 \mathrm{dS} / \mathrm{m}\right.$ e $\left.\mathrm{S}_{4}=4.00 \mathrm{dS} / \mathrm{m}\right)$ on vegetative growth in bananas Pacovan (AAB) and Marmelo (ABB) were evaluated. The experiment was carried out on a sandy clay loam Chromic Argisol in a split-plot scheme arranged in a randomized block design with four replications. The whole plots were composed of a row with 10-plants, five plants of each cultivar (subplot), and the data were collected from the three central ones. The irrigations were applied either dayly or every each two-days period in order to maintain a lixiviation fraction of 0.15 , using approximate water sheets to keep the soil at field capacity. The data obtained at 110,160 , 220,300 , and 360 days after planting indicated that the water salinity level increase caused plant height, number of leaves, and leaf area to decrease significantly up to 240 days of the growth period, with the values becoming equalled after the rainy period.

Index terms: Banana, salinity, irrigation, sodicity.

\section{INTRODUCÃO}

O Nordeste brasileiro é a principal região produtora de bananas, com mais de $39 \%$ da área total do país, cerca de 166.887 ha de área colhida e uma produção em torno de $1.660 .685 \mathrm{Mg} / \mathrm{ano}$ (AGRIANUAL, 2000), possuindo em quase toda a sua extensão condições climáticas tropicais para o desenvolvimento e produção da cultura. Apesar dessas condições favoráveis, a produtividade obtida tem sido aquém do seu potencial, devido a não utilização de tecnologias disponíveis e adequadas para a sua exploração. A salinização das áreas irrigadas, nas regiões áridas e semi-áridas do mundo inteiro é notória. No Nordeste do Brasil, tem-se constatado problemas de salinidade, praticamente, em todos os grandes perímetros irrigados. Normalmente a salinidade em áreas irrigadas é conseqüência do uso de água de qualidade não adequada, associado ao manejo do solo-água-planta (Medeiros et al., 1993). O objetivo desta pesquisa foi avaliar os efeitos da salinidade da água de irrigação nas bananeiras Pacovan (AAB) e Marmelo (ABB), no seu desenvolvimento vegetativo.

\section{MATERIALE MÉTODOS}

\section{Características da área experimental}

O experimento foi desenvolvido na área do Parque Zôo-botânico da Escola Superior de Agricultura de Mossoró-RN - ESAM, entre julho de 1999 e janeiro do ano 2001. O solo da área experimental utilizada foi classificado como Argissolo Crômico, textura franco-argilo-arenosa (EMBRAPA, 1999) e os resultados das análises químicas e físicas realizadas no Laboratório de Solos da ESAM (Tabela 1). O relevo da área é considerado plano a suave ondulado. O município de Mossoró está situado na região semi-árida do Nordeste brasileiro, no Estado do Rio Grande do Norte, localizado pelas coordenadas geográficas $5^{\circ} 11^{\prime}$ de latitude sul, $37^{\circ} 20^{\prime}$ de longitude W. Gr. e $18 \mathrm{~m}$ de altitude, com uma temperatura média anual em torno de $27,5^{\circ} \mathrm{C}$, umidade relativa de $68,9 \%$, nebulosidade média anual de 4,4 décimos e precipitação média anual de 673,9 mm. Segundo classificação climática de Köppen, o clima de MossoróRN é do tipo BSwh', ou seja, quente e seco, tipo estepe, com estação chuvosa no verão atrasando-se para o outono (Carmo Filho et al., 1987).

TABELA 1 - Características químicas do solo da área experimental:

\begin{tabular}{|c|c|c|c|c|c|c|c|c|c|c|c|}
\hline \multirow[t]{2}{*}{ ÉPOCA } & \multirow[t]{2}{*}{ PROF } & \multicolumn{3}{|c|}{$\mathrm{pH}(1: 2,5)$} & $\mathrm{Ca}$ & $\mathrm{Mg}$ & $\mathrm{K}$ & $\mathrm{Na}$ & $\mathrm{Al}$ & $\mathrm{P}$ & CEes \\
\hline & & $\mathrm{H}_{2} \mathrm{O}$ & $\mathrm{KCl}$ & $\mathrm{CaCl}_{2}$ & \multicolumn{5}{|c|}{$\left(\mathrm{cmolc} / \mathrm{dm}^{3}\right)$} & $\left(\mathrm{mg} / \mathrm{dm}^{3}\right)$ & $\left(\mathrm{dS} . \mathrm{m}^{-1}\right)$ \\
\hline \multirow{2}{*}{$\begin{array}{l}\text { ANTES DO } \\
\text { PLANTIO }\end{array}$} & $0-20$ & 6,9 & - & - & 4,6 & 4,6 & 0,35 & 0,30 & 0,0 & 80 & 2,8 \\
\hline & $20-40$ & 6,3 & - & - & 4,4 & 4,4 & 0,36 & 0,21 & 0,0 & 100 & 2,5 \\
\hline 10 MESES & $0-20$ & 7,7 & 6,5 & 7,0 & 3,4 & 1,7 & 0,26 & 0,30 & 0,0 & 102 & - \\
\hline APOS & $20-40$ & 7,7 & 6,5 & 7,0 & 3,7 & 1,85 & 0,31 & 0,38 & 0,0 & 100 & - \\
\hline
\end{tabular}

\footnotetext{
${ }^{1}$ (Trabalho 143/2002). Recebido: 20/09/2002. Aceito para publicação: 31/10/2003. Parte da Dissertação de Mestrado do primeiro autor, ESAM-RN.

${ }^{2}$ Professor EAF de Iguatu-CE, M.Sc. Fitotecnia, Rua Eng. Barreto, 524, CEP 63.500-000, Iguatu-CE.

${ }^{3}$ Professor ESAM-RN, Km 47 BR 110, B. Costa e Silva, CEP 59625-900, Mossoró-RN.

${ }^{4}$ Professor UFPB, Av. Aprígio Veloso, 882, Bodocongó, CEP 58.109-970, Campina Grande - PB.

${ }^{5}$ Engenheiro Agrônomo - ESAM-RN, Km 47 BR 110, B. Costa e Silva, CEP 59625-900, Mossoró-RN.

${ }^{6}$ Professor EAF de Iguatu-CE, Lic. em Ciências Agrícolas, Rua Tancredo Neves, 82, CEP 63.5500-000. Iguatu-CE.
} 


\section{Tratamentos e delineamento experimental}

Os fatores estudados nos tratamentos foram quatro níveis de salinidade da água $\left(\mathrm{S}_{1}=0,55 \mathrm{dS} / \mathrm{m}, \mathrm{S}_{2}=1,7 \mathrm{dS} / \mathrm{m}, \mathrm{S}_{3}=2,8 \mathrm{dS} / \mathrm{m} \mathrm{e}_{4}=4,0 \mathrm{dS} /\right.$ $\mathrm{m})$ e dois cultivares de bananeiras: Pacovan (AAB) e Marmelo (ABB). $\mathrm{O}$ delineamento experimental adotado foi em blocos completos inteiramente casualizados em parcelas subdivididas $4 \times 2$, com quatro repetições, totalizando 8 tratamentos. O espaçamento utilizado foi o de $3,0 \times 2,0 \mathrm{~m}$ e as parcelas experimentais foram compostas de uma fileira com 10 plantas, sendo cinco plantas da cultivar Pacovan e cinco da cultivar Marmelo, com as três plantas centrais de cada sub-parcela consideradas úteis.

\section{Irrigação e preparo das águas}

O sistema de irrigação utilizado foi o de gotejamento com duas linhas laterais por fileira e quatro gotejadores por planta, com vazão de $3,75 \mathrm{~L} / \mathrm{h}$ cada.A lâmina de irrigação era controlada pelo tempo, usandose abertura e fechamento das válvulas. Os níveis de salinidade foram obtidos a partir de misturas de águas naturais de poços do arenito $(\mathrm{CE}=0,55 \mathrm{dS} / \mathrm{m})$ e do aqüífero calcário $(\mathrm{CE}=4,0 \mathrm{dS} / \mathrm{m})$, sendo estas armazenadas em tanques de alvenaria revestidos de cimento, com os níveis de salinidade pré-estabelecidos e verificados diariamente com o auxílio de condutivímetro. As irrigações foram feitas diariamente ou a cada dois dias, de modo a proporcionar uma fração de lixiviação de $0,15 \%$, colocando-se volumes aproximados de água para manter o solo próximo à capacidade de campo. As necessidades hídricas da cultura foram estimadas conforme metodologia recomendada por Allen et al., 1996. Ao longo do ciclo, a umidade do solo foi monitorada por tensiômetros. As baterias de tensiômetros foram instaladas nas oito subparcelas de um bloco e nas profundidades de 15,30 e $45 \mathrm{~cm}$.

\section{Preparo do solo, plantio e adubação}

Constou de uma aração e uma gradagem para melhorar aeração e nivelamento do mesmo e foi amostrado nas profundidades de $0-20$, $20-40$ e 40-60 cm para a realização de análises químicas. Foi adubado conforme resultados das análises feitas no Laboratório de Fertilidade de Solo da ESAM que estão apresentadas na Tabela 1. A adubação de fundação foi feita, visando a correção do solo, acrescida de $5 \mathrm{~kg}$ de esterco de ave curtido por cova e, as adubações de manutenção foram feitas via água de irrigação de acordo com a necessidade nutricional da cultura. O plantio ocorreu na primeira quinzena de agosto, feito em covas de 50x50x50 cm de profundidade. As mudas da cultivar Pacovan ficaram armazenadas por duas semanas devido à falta de mudas da cultivar Marmelo e a quantidade utilizada foi de 80 de cada cultivar e todas do tipo chifre. Durante o primeiro mês após o plantio, foram feitas irrigações com água de $0,55 \mathrm{dS} / \mathrm{m}$, usando-se 10 a $15 \mathrm{~L} /$ planta a cada dois dias até iniciar pegamento destas. Após 30 dias começaramse os tratamentos com águas salinas com duração de 1 hora, o que corresponde a $15 \mathrm{~L} /$ cova, realizada a cada dois dias no segundo mês. A partir do terceiro mês, as irrigações foram feitas diariamente.

\section{Observações experimentais}

A partir dos 110 dias após o plantio das mudas no campo, foram realizadas as medições de altura de plantas, diâmetro de pseudocaule, número de folhas, área foliar unitária e área foliar total.

\section{RESULTADOS E DISCUSSÃO}

Efeitos dos níveis de salinidade da água de irrigação na evolução da salinidade e na umidade do solo

A evolução da salinidade no solo a partir dos valores de condutividade elétrica do extrato de saturação (CEes), ao longo do tempo, nas diferentes profundidades e épocas, encontra-se na Figura 1. O maior acúmulo de sais no solo na época inicial (sem chuvas) ocorreu, provavelmente, devido à elevada evapotranspiração e irrigação com as respectivas águas aplicadas com frações de lixiviação inferior a $0,15 \%$. Nos períodos de chuvas (150 a 300 dias), constataram-se diminuições dos teores de sais no solo, onde a CEes foi notadamente reduzida, ficando inclusive abaixo de todos os níveis de salinidade da água de irrigação. No período sem chuva subseqüente, como as lâminas de irrigação proporcionaram frações de lixiviação maiores ( $F L>0,15)$, a salinidade do solo cresceu menos do que na fase inicial de cultivo. Rhoades et al. (1992) afirmam que as lixiviações mais intensas são obtidas com chuvas ou irrigações sucessivas, e são as responsáveis pelo controle da lixiviação dos sais do solo. De acordo com a Figura 2, a salinidade média do solo ponderada com o tempo pode ser explicada pelo modelo potencial ou linear em função da salinidade da água. Verificase que houve acúmulo de sais no solo, na profundidade estudada, sendo proporcionais aos níveis de salinidade da água de irrigação, principalmente no final do ciclo.

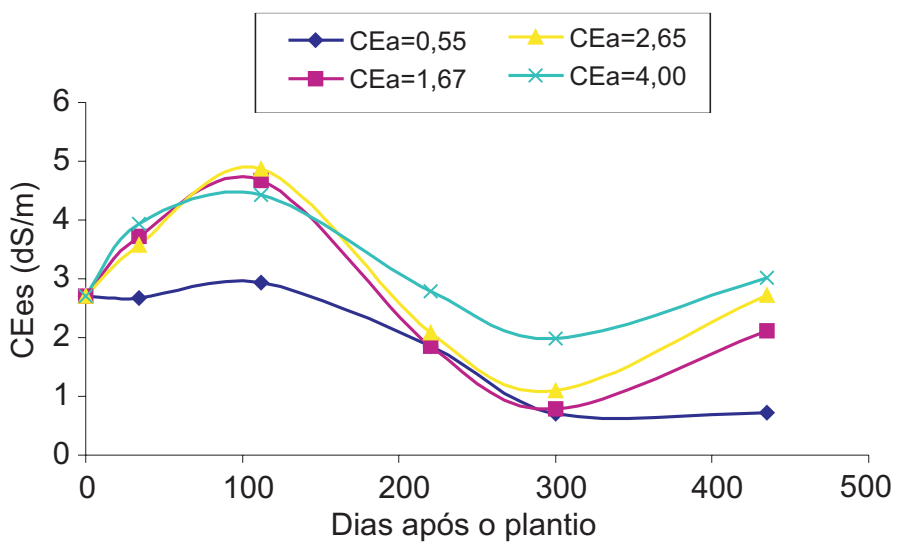

FIGURA 1 - Evolução da salinidade do solo ao longo do ciclo cultural para cada água de irrigação, na camada de $0-60 \mathrm{~cm}$ de profundidade, em Mossoró, RN.

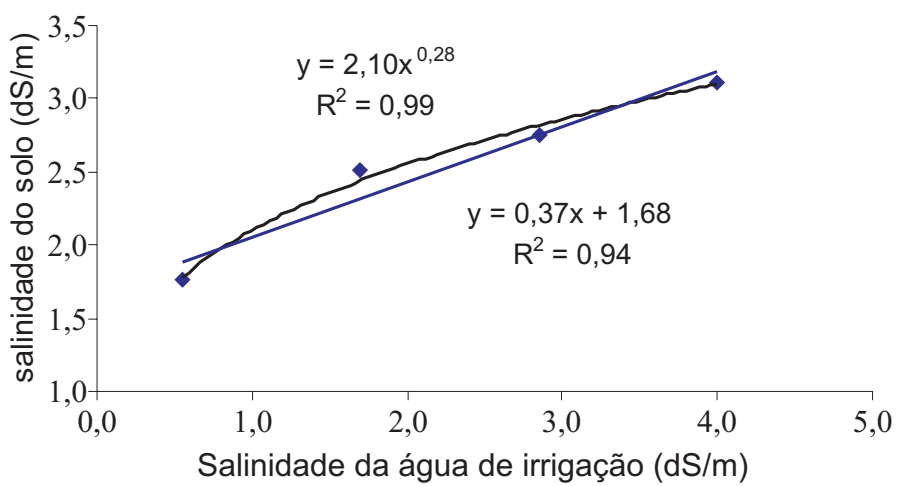

FIGURA 2 - Relação entre a salinidade do solo média ponderada ao longo do tempo para a camada de $0-60 \mathrm{~cm}$ e a salinidade da água de irrigação, em Mossoró, RN.

Efeitos de diferentes níveis de salinidade da água de irrigação no desenvolvimento das bananeiras Pacovan e Marmelo (Musa sp.) -Altura de Plantas

A altura das plantas foi significativamente afetada pela salinidade da água de irrigação aos 110, 160 e 240 dias, apresentando efeito linear. A Tabela 2 mostra as equações de regressão e os coeficientes de determinação, onde se verifica redução da altura das plantas com o aumento da salinidade da água de irrigação para essas épocas. Observase na Figura 3 a altura das plantas para cada nível de salinidade em cada época e que, para os níveis de salinidade $\mathrm{S}_{3}$ e $\mathrm{S}_{4}$ houve um crescimento 
TABELA 6 - Resumo da análise de variância e médias da altura em cm, de plantas de bananeiras Pacovan e Marmelo, aos 110, 160, 240, 300 e 360 dias em função dos diferentes níveis de salinidade da água de irrigação. Mossoró - RN, 2000.

\begin{tabular}{|c|c|c|c|c|c|c|}
\hline \multirow[b]{2}{*}{ F.V. } & \multirow[b]{2}{*}{ G.L. } & \multicolumn{5}{|c|}{ Idade da planta } \\
\hline & & 110 & 160 & 240 & 300 & 360 \\
\hline & & \multicolumn{5}{|c|}{ Estatística F } \\
\hline BLOCO & 3 & $0,22^{\mathrm{ns}}$ & $5,31^{*}$ & $0,92^{\text {ns }}$ & $0,60^{\mathrm{ns}}$ & $1,92^{\mathrm{ns}}$ \\
\hline SALINIDADE & 3 & $6,23 *$ & $2,11^{\mathrm{ns}}$ & $20 * *$ & $1,63^{\mathrm{ns}}$ & $1,03^{\mathrm{ns}}$ \\
\hline Linear & 1 & $15,17^{* *}$ & $5,74^{*}$ & $55^{* *}$ & $4,82^{\mathrm{ns}}$ & $0,67^{\mathrm{ns}}$ \\
\hline Quadrática & 1 & $3,23^{\mathrm{ns}}$ & $0,45^{\mathrm{ns}}$ & $1,70^{\mathrm{ns}}$ & $0,011^{\mathrm{ns}}$ & $1,07^{\mathrm{ns}}$ \\
\hline Cúbica & 1 & $0,30^{\mathrm{ns}}$ & $0,132^{\text {ns }}$ & $2,50^{\mathrm{ns}}$ & $0,65^{\mathrm{ns}}$ & $1,33^{\mathrm{ns}}$ \\
\hline QMRes (a) & 9 & 0,0106 & 0,188 & 0,056 & 0,0846 & 0,0327 \\
\hline & & \multicolumn{5}{|c|}{ Estatística $\mathbf{F}$} \\
\hline CULTIVAR & 1 & $4,82^{*}$ & $0,79^{\mathrm{ns}}$ & $0,21^{\mathrm{ns}}$ & $1,46^{\mathrm{ns}}$ & $0,21^{\mathrm{ns}}$ \\
\hline CULT x SAL & 3 & $3,00^{\mathrm{ns}}$ & $2,12^{\mathrm{ns}}$ & $1,04^{\mathrm{ns}}$ & $0,79^{\mathrm{ns}}$ & $2,83^{\mathrm{ns}}$ \\
\hline QMRes (b) & 12 & 48,6 & 0,0241 & 0,0855 & 0,0758 & 0,0459 \\
\hline \multicolumn{2}{|l|}{ CV (\%) } & 14,3 & 18,8 & 21,0 & 13,3 & 9,36 \\
\hline CULTIVAR & & \multicolumn{5}{|c|}{ Médias $^{\#}$} \\
\hline \multirow{2}{*}{\multicolumn{2}{|c|}{$\begin{array}{l}\mathrm{C}_{1}-\text { Pacovan } \\
\mathrm{C}_{2}-\text { Marmelo }\end{array}$}} & $0,46 \mathrm{~b}$ & $0,84 \mathrm{a}$ & $1,42 \mathrm{a}$ & $2,02 \mathrm{a}$ & $2,27 \mathrm{a}$ \\
\hline & & $0,51 \mathrm{a}$ & $0,82 \mathrm{a}$ & $1,37 \mathrm{a}$ & $2,14 \mathrm{a}$ & $2,31 \mathrm{a}$ \\
\hline \multicolumn{7}{|l|}{ SALINIDADE } \\
\hline $\mathrm{S}_{1}(\mathrm{CE}=0,55)$ & & $0,62 \mathrm{a}$ & $1,14 \mathrm{a}$ & $1,90 \mathrm{a}$ & $2,22 \mathrm{a}$ & $2,28 \mathrm{a}$ \\
\hline $\mathrm{S}_{2}(\mathrm{CE}=1,70)$ & & $0,47 \mathrm{a}$ & $0,82 \mathrm{a}$ & $1,39 \mathrm{a}$ & $2,15 \mathrm{a}$ & $2,38 \mathrm{a}$ \\
\hline $\mathrm{S}_{3}(\mathrm{CE}=2,85)$ & & $0,44 \mathrm{a}$ & $0,73 \mathrm{a}$ & $1,28 \mathrm{a}$ & $2,01 \mathrm{a}$ & $2,26 \mathrm{a}$ \\
\hline $\mathrm{S}_{4}(\mathrm{CE}=4,00)$ & & $0,42 \mathrm{a}$ & $0,62 \mathrm{a}$ & $1,00 \mathrm{~b}$ & $1,92 \mathrm{a}$ & $2,23 \mathrm{a}$ \\
\hline
\end{tabular}

\# Médias seguidas da mesma letra, na coluna, não diferem entre si $(\mathrm{P}>0,05)$ pelo teste de Tukey.

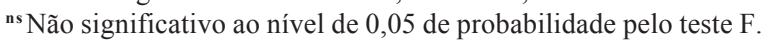

* Significativo ao nível de 0,05 de probabilidade pelo teste F.

** Significativo ao nível de 0,01 de probabilidade pelo teste $\mathrm{F}$.

TABELA 2 - Equações de regressão e coeficiente de determinação para altura de plantas em função do nível de salinidade da água de irrigação para diferentes épocas.

\begin{tabular}{ccc}
\hline Idade da planta & Equação & $\mathrm{r}^{2}$ \\
\hline 110 dias & $\mathrm{Y}=-0,055 \mathrm{x}+0,612$ & 0,81 \\
160 dias & $\mathrm{Y}=-0,143 \mathrm{x}+1,15$ & 0,91 \\
240 dias & $\mathrm{Y}=-0,242 \mathrm{x}+1,94$ & 0,93 \\
\hline
\end{tabular}

mais acentuado ente 240 e 300 dias, continuando até 360 dias, fato não ocorrido para os níveis $\mathrm{S}_{1}$ e $\mathrm{S}_{2}$. Isto, provavelmente, foi devido ao período chuvoso, entre 150 e 270 dias, e à redução da salinidade do solo, principalmente para os níveis de salinidade mais elevados (Figura 1), como também, pelo fato das plantas dos níveis $\mathrm{S}_{1}$ e $\mathrm{S}_{2}$ já estarem no final do ciclo reprodutivo, o que fez a planta paralisar o crescimento. Santos (1997) também verificou a recuperação de plantas estressadas por sais no período seco após o período chuvoso. Entretanto, para cultivares, houve efeito significativo apenas para 110 dias. Verificou-se, também, efeito não interativo entre cultivares e salinidade da água de irrigação, ou seja, ambas as cultivares foram afetadas semelhantemente pela salinidade. A cultivar Marmelo foi superior a Pacovan em altura na medição inicial, provavelmente, devido ao fato de terem sido adquiridas em pomares diferentes e a Pacovan ter ficado armazenada alguns dias antes do plantio, o que fez com que parte de suas reservas nutricionais fossem consumidas, enquanto a Marmelo teve o plantio imediatamente após a sua retirada. Considerando a altura de planta no final do ciclo, verificou-se que as cultivares não atingiram a sua altura potencial (Tabela 6). De maneira geral, o menor crescimento e desenvolvimento vegetativo das plantas em tratamentos mais salinos podem ser associados à diminuição da absorção de água pelas plantas, dado o aumento da pressão osmótica da solução do solo provocado por acumulações de sais solúveis provenientes das águas de irrigação (Ayres \& Westcot 1991). Araújo Filho (1990) verificou, comparando cultivares de bananeiras, a um determinado nível de salinidade do solo, que as cultivares do grupo AAA apresentaram maior tolerância que as do grupo $\mathrm{AAB}$, embora não tenha sido possível estabelecer os valores de salinidade limiar para a bananeira, pois houve uma redução linear, desde o menor nível de salinidade estudado $(0,9 \mathrm{dS} / \mathrm{m})$, para a maioria dos parâmetros avaliados, sobretudo para a Pacovan. Santos (1990) e Santos (1997) também verificaram reduções na altura de plantas de bananeiras Nanica em função da salinidade da água de irrigação, em diferentes idades.

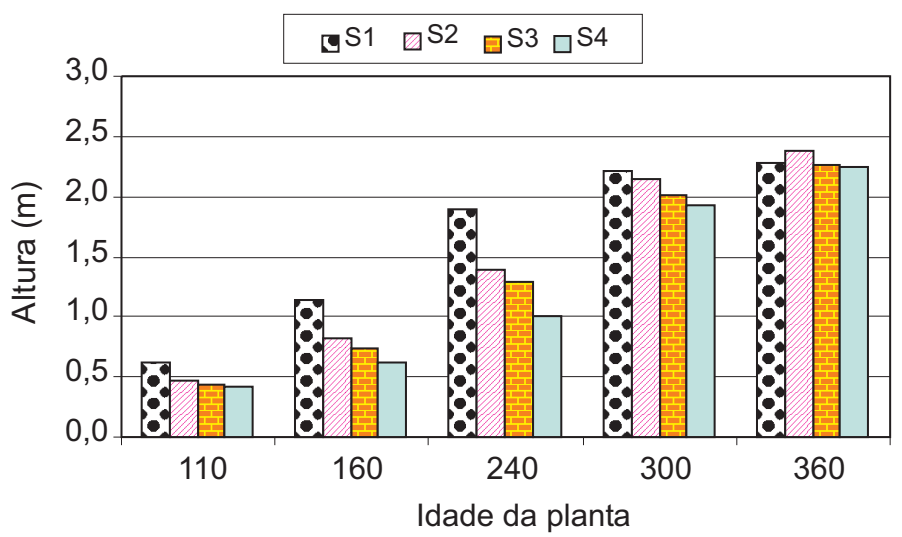

FIGURA 3 - Altura de plantas de bananeira ao longo do ciclo para diferentes níveis de salinidade da água de irrigação, em Mossoró, RN.

\section{Diâmetro de Pseudocaule}

A salinidade da água de irrigação afetou de forma significativa o diâmetro do pseudocaule, tendo efeito linear para 110, 240 e 300 dias e cúbico para 160 dias, embora linear já explique em $81 \%$ e não significativo $(\mathrm{P}>0,05)$ para 360 dias. ATabela 3 apresenta as equações de regressão e os respectivos coeficientes de determinação. Através da Figura 4, verificase, também, que, para o final do ciclo, o efeito da salinidade sobre o diâmetro do pseudocaule foi menos acentuado, o que pode ter ocorrido devido à planta cessar o seu desenvolvimento vegetativo, logo iniciando a sua diferenciação floral, o que aconteceu mais precocemente, quanto menos salina era a água de irrigação, pelo fato da redução da salinidade do solo, entre os tratamentos, em decorrência do período chuvoso ter ocorrido entre o $6^{\circ}$ e $11^{\circ}$ mês do cultivo (Tabela 7). Santos (1990) observou efeito semelhante da salinidade para o diâmetro do pseudocaule, estudando a bananeira Nanica, entretanto, o mesmo constatou maior efeito da salinidade à medida que as plantas foram ficando mais velhas. 
TABELA 7 - Resumo da análise de variância e médias do diâmetro do pseudocales em cm, de plantas de bananeiras Pacovan e Marmelo, aos 110 , 160, 240, 300 e 360 dias, em função dos diferentes níveis de salinidade da água de irrigação. Mossoró - RN, 2000.

\begin{tabular}{|c|c|c|c|c|c|c|}
\hline \multirow[b]{2}{*}{ F.V. } & \multirow[b]{2}{*}{ G.L. } & \multicolumn{5}{|c|}{ Idade da planta } \\
\hline & & 110 & 160 & 240 & 300 & 360 \\
\hline & & \multicolumn{5}{|c|}{ Estatística F } \\
\hline BLOCO & 3 & 0,122 & 1,03 & 1,48 & 1,77 & 1,40 \\
\hline SALINIDADE & 3 & $6,90 *$ & $29,26^{* *}$ & $31,72^{* *}$ & $4,93 *$ & $0,62^{\mathrm{ns}}$ \\
\hline Linear & 1 & $16,85^{* *}$ & $71,26^{* *}$ & $88,88 * *$ & $14,55 * *$ & $1,17^{\mathrm{ns}}$ \\
\hline Quadrática & 1 & $3,60^{\mathrm{ns}}$ & $9,65^{*}$ & $2,37^{\mathrm{ns}}$ & $0,01^{\mathrm{ns}}$ & $0,56^{\mathrm{ns}}$ \\
\hline Cúbica & 1 & $0,278^{*}$ & $6,78 *$ & $4,00^{\mathrm{ns}}$ & $0,28^{\mathrm{ns}}$ & $0,13^{\mathrm{ns}}$ \\
\hline QMRes (a) & 9 & 0,611 & 0,943 & 1,80 & 1,80 & 0,60 \\
\hline & & \multicolumn{5}{|c|}{ Estatística F } \\
\hline CULTIVAR & 1 & $4,50^{\mathrm{ns}}$ & $0,01^{\mathrm{ns}}$ & $0,06^{\mathrm{ns}}$ & $1,20^{\mathrm{ns}}$ & $1,76^{\mathrm{ns}}$ \\
\hline CULT x SAL & 3 & $0,84^{\mathrm{ns}}$ & $1,67^{\mathrm{ns}}$ & $0,90^{\mathrm{ns}}$ & $0,30^{\mathrm{ns}}$ & $0,57^{\mathrm{ns}}$ \\
\hline QMRes (b) & 12 & 0,340 & 1,68 & 3,74 & 1,54 & 1,33 \\
\hline CV $(\%)$ & & 13,3 & 15,7 & 16,5 & 8,02 & 6,84 \\
\hline CULTIVAR & & \multicolumn{5}{|c|}{ Médias\# } \\
\hline $\mathrm{C}_{1}$ - Pacovan & & $4,2 \mathrm{a}$ & $8,5 \mathrm{a}$ & $11,8 \mathrm{a}$ & $15,2 \mathrm{a}$ & $16,6 \mathrm{a}$ \\
\hline $\mathrm{C}_{2}$ - Marmelo & & $4,6 \mathrm{a}$ & $8,0 \mathrm{a}$ & $11,7 \mathrm{a}$ & $15,7 \mathrm{a}$ & $17,1 \mathrm{a}$ \\
\hline SALINIDADE & & & & & & \\
\hline $\mathrm{S}_{1}(\mathrm{CE}=0,55)$ & & $5,4 \mathrm{a}$ & $10,9 \mathrm{a}$ & $15,3 \mathrm{a}$ & $16,6 \mathrm{a}$ & $16,9 \mathrm{a}$ \\
\hline $\mathrm{S}_{2}(\mathrm{CE}=1,70)$ & & $4,3 \mathrm{a}$ & $7,8 \mathrm{~b}$ & $11,7 \mathrm{a}$ & $16,1 \mathrm{a}$ & $17,1 \mathrm{a}$ \\
\hline $\mathrm{S}_{3}(\mathrm{CE}=2,85)$ & & $4,0 \mathrm{a}$ & $7,7 \mathrm{~b}$ & $11,0 \mathrm{~b}$ & $14,9 \mathrm{a}$ & $16,8 \mathrm{a}$ \\
\hline $\mathrm{S}_{4}(\mathrm{CE}=4,00)$ & & $3,8 \mathrm{a}$ & $6,6 \mathrm{~b}$ & $8,9 \mathrm{~b}$ & $14,3 \mathrm{a}$ & $16,6 \mathrm{a}$ \\
\hline
\end{tabular}

\# Médias seguidas da mesma letra, na coluna, não diferem entre si (P>0,05) pelo teste de Tukey.

${ }^{\text {ns }}$ Não significativo ao nível de 0,05 de probabilidade pelo teste $\mathrm{F}$.

* Significativo ao nível de 0,05 de probabilidade pelo teste $\mathrm{F}$.

** Significativo ao nível de 0,01 de probabilidade pelo teste $\mathrm{F}$.

Nesse caso, o autor atribuiu ao aumento da salinidade do solo ao longo do ciclo cultural.

TABELA 3 - Equações de regressão e coeficiente de determinação para diâmetro do pseudocaule, em função do nível de salinidade da água de irrigação, para diferentes épocas.

\begin{tabular}{ccc}
\hline Idade da planta & Equação & $\mathrm{r}^{2}$ \\
\hline 110 dias & $\mathrm{Y}=-0,44 \mathrm{x}+5,37$ & 0,82 \\
160 dias & $\mathrm{Y}=-1,13 \mathrm{x}+10,83$ & 0,81 \\
240 dias & $\mathrm{Y}=-1,74 \mathrm{x}+15,70$ & 0,93 \\
300 dias & $\mathrm{Y}=-0,70 \mathrm{x}+17,08$ & 0,98 \\
\hline
\end{tabular}

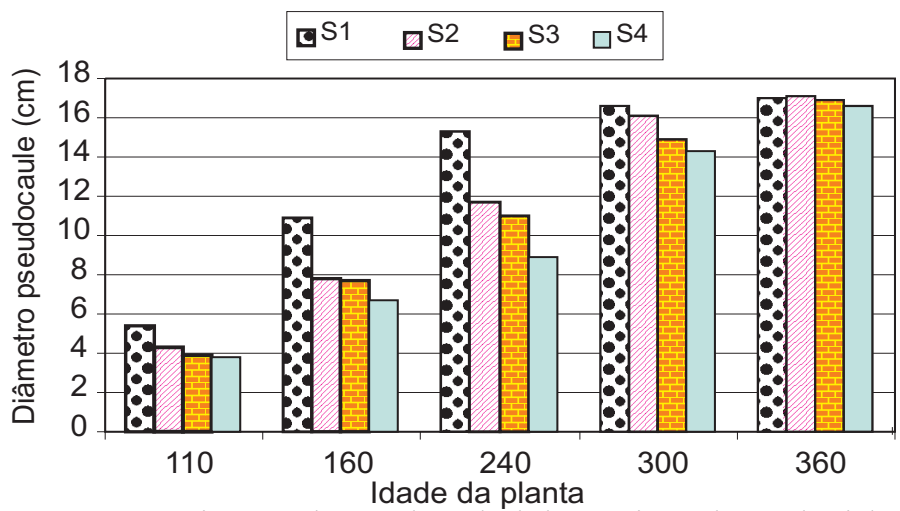

FIGURA 4 -Diâmetro do pseudocaule de bananeira ao longo do ciclo para diferentes níveis de salinidade da água de irrigação, em Mossoró, RN.

\section{Número de Folhas}

Esta característica foi afetada significativamente pela salinidade da água de irrigação, exceto aos 300 e 360 dias, tendo um efeito linear para as plantas com 110, 160, 240 e 360 dias. A Tabela 4 apresenta as equações de regressão e os respectivos coeficientes de determinação. Observa-se, na Figura 5, que a partir de 160 dias o efeito da salinidade foi ficando cada vez menor, passando a ter efeito positivo aos 360 dias, ou seja, a salinidade da água de irrigação aumentou o número de folhas por planta. Isto, provavelmente, devido às plantas irrigadas com menores níveis de salinidade entrarem no estágio de diferenciação floral mais cedo, paralisando assim o seu crescimento vegetativo, e de ter havido redução da salinidade do solo entre os tratamentos, promovida pelas chuvas ocorridas a partir do $150^{\circ}$ dia de cultivo. Todavia, para cultivares, houve efeito significativo apenas aos 110 dias. Verificou-se, também, efeito não interativo entre cultivares e salinidade da água de irrigação, ou seja, que ambas as cultivares foram afetadas igualmente pela salinidade. Santos (1990) observou que, de maneira geral, folhas de plantas de bananeiras Nanica irrigadas com águas contendo concentrações salinas maiores tiveram crescimento lentos e, conseqüentemente, períodos de abertura maiores.

TABELA4 - Equações de regressão e coeficiente de determinação para número de folhas por planta em função do nível de salinidade da água de irrigação para diferentes épocas.

\begin{tabular}{ccc}
\hline Idade da planta & Equação & $\mathrm{r}^{2}$ \\
\hline 110 dias & $\mathrm{Y}=-1,23 \mathrm{x}+12,59$ & 0,97 \\
160 dias & $\mathrm{Y}=-1,53 \mathrm{x}+15,21$ & 0,97 \\
240 dias & $\mathrm{Y}=-0,79 \mathrm{x}+15,90$ & 0,93 \\
360 dias & $\mathrm{Y}=0,10 \mathrm{x}+14,02$ & 0,55 \\
\hline
\end{tabular}

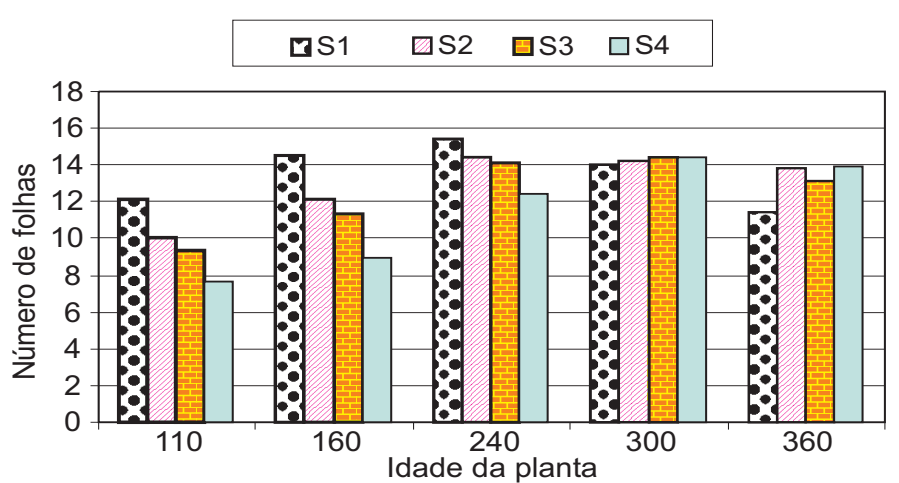

FIGURA 5 - Número de folhas por planta de bananeira ao longo do ciclo para diferentes níveis de salinidade da água de irrigação, em Mossoró, RN. 
TABELA 8 - Resumo da análise de variância e médias da área foliar total em $\mathrm{cm}^{2}$, de plantas de bananeiras Pacovan e Marmelo aos 110, 160, 240, 300 e 360 dias em função dos diferentes níveis de salinidade da água de irrigação. Mossoró - RN, 2000.

\begin{tabular}{|c|c|c|c|c|c|c|}
\hline \multirow[b]{2}{*}{ F.V. } & \multirow[b]{2}{*}{ G.L. } & \multicolumn{5}{|c|}{ Idade da planta } \\
\hline & & 110 & 160 & 240 & 300 & 360 \\
\hline & & \multicolumn{5}{|c|}{ Estatística $\mathrm{F}$} \\
\hline BLOCO & 3 & $0,27^{\mathrm{ns}}$ & $0,44^{\mathrm{ns}}$ & $0,55^{\mathrm{ns}}$ & $1,38^{\mathrm{ns}}$ & $0,32^{\mathrm{ns}}$ \\
\hline SALINIDADE & 3 & $9,64^{* *}$ & $0,69^{\mathrm{ns}}$ & $11,25^{* *}$ & $0,25^{\mathrm{ns}}$ & $1,87^{\mathrm{ns}}$ \\
\hline Linear & 1 & $25,39 * *$ & $0,47^{\mathrm{ns}}$ & $32,57 * *$ & $0,36^{\mathrm{ns}}$ & $0,89^{\mathrm{ns}}$ \\
\hline Quadrática & 1 & $3,00^{\mathrm{ns}}$ & $0,28^{\mathrm{ns}}$ & $0,16^{\mathrm{ns}}$ & $0,30^{\mathrm{ns}}$ & $2,37^{\mathrm{ns}}$ \\
\hline Cúbica & 1 & $0,515^{\mathrm{ns}}$ & $1,30^{\mathrm{ns}}$ & $1,50^{\mathrm{ns}}$ & $0,09^{\text {ns }}$ & $2,34^{\mathrm{ns}}$ \\
\hline QMRes (a) & 9 & 0,504 & 3,78 & 4,39 & 5,30 & 3,89 \\
\hline & & \multicolumn{5}{|c|}{ Estatística $\mathbf{F}$} \\
\hline CULTIVAR & 1 & $6,67^{*}$ & $0,27^{\mathrm{ns}}$ & $0,03^{\text {ns }}$ & $0,03^{\mathrm{ns}}$ & $0,47^{\mathrm{ns}}$ \\
\hline CULT x SAL & 3 & $1,96^{\mathrm{ns}}$ & $0,76^{\mathrm{ns}}$ & $1,50^{\mathrm{ns}}$ & $1,12^{\mathrm{ns}}$ & $0,98^{\mathrm{ns}}$ \\
\hline QMRes (b) & 12 & 0,85 & 2,35 & 4,69 & 6,06 & 2,18 \\
\hline CV $(\%)$ & & 28,8 & 39,1 & 31,9 & 22,9 & 14,86 \\
\hline CULTIVAR & & \multicolumn{5}{|c|}{ Médias\# } \\
\hline \multirow{2}{*}{\multicolumn{2}{|c|}{$\begin{array}{c}\mathrm{C}_{1}-\text { Pacovan } \\
\mathrm{C}_{2}-\text { Marmelo }\end{array}$}} & $1,69 \mathrm{a}$ & $4,33 \mathrm{a}$ & $6,85 \mathrm{a}$ & $10,7 \mathrm{a}$ & $9,8 \mathrm{a}$ \\
\hline & & $1,30 \mathrm{~b}$ & $3,51 \mathrm{a}$ & $6,73 \mathrm{a}$ & $10,8 \mathrm{a}$ & $10,1 \mathrm{a}$ \\
\hline \multicolumn{7}{|l|}{ SALINIDADE } \\
\hline $\mathrm{S}_{1}(\mathrm{CE}=0,55)$ & & $2,60 \mathrm{a}$ & $3,88 \mathrm{a}$ & $9,95 \mathrm{a}$ & $10,8 \mathrm{a}$ & $8,7 \mathrm{a}$ \\
\hline $\mathrm{S}_{2}(\mathrm{CE}=1,70)$ & & $1,44 \mathrm{a}$ & $4,74 \mathrm{a}$ & $7,08 \mathrm{a}$ & $11,3 \mathrm{a}$ & $11,0 \mathrm{a}$ \\
\hline $\mathrm{S}_{3}(\mathrm{CE}=2,85)$ & & $1,11 \mathrm{a}$ & $3,47 \mathrm{a}$ & $6,21 \mathrm{a}$ & $10,7 \mathrm{a}$ & $9,9 \mathrm{a}$ \\
\hline $\mathrm{S}_{4}(\mathrm{CE}=4,00)$ & & $0,83 \mathrm{a}$ & $3,59 \mathrm{a}$ & $3,94 \mathrm{~b}$ & $10,3 \mathrm{a}$ & $10,1 \mathrm{a}$ \\
\hline
\end{tabular}

\# Médias seguidas da mesma letra, na coluna, não diferem entre si $(\mathrm{P}<0,05)$ pelo teste de Tukey.

${ }^{\text {ns }}$ Não significativo ao nível de 0,05 de probabilidade pelo teste $\mathrm{F}$.

* Significativo ao nível de 0,05 de probabilidade pelo teste $\mathrm{F}$.

** Significativo ao nível de 0,01 de probabilidade pelo teste $\mathrm{F}$.

\section{Área Foliar Total}

Verifica-se que a área foliar total das plantas foi significativamente afetada pela salinidade da água de irrigação aos 110 e 240 dias, apresentando efeito linear. A Tabela 5 mostra as equações de regressão e os respectivos coeficientes de determinação. Entretanto, para cultivares, houve efeito significativo apenas para 110 dias. Observou-se, também, efeito não interativo entre cultivares e salinidade da água de irrigação, ou seja, que ambas as cultivares foram afetadas igualmente pela salinidade. Na Figura 6, observa-se a maior taxa de crescimento até 240 dias, para as médias menos salinas, e que as para águas $\mathrm{S}_{3}$ e $\mathrm{S}_{4}$ a maior taxa de crescimento ocorreu entre 240 e 300 dias, confrontando os resultados verificados entre as variáveis de crescimento (Tabela 8). Santos (1990) constatou que os efeitos dos níveis de salinidade foram muito acentuados, principalmente nos tratamentos com concentrações a partir de $25 \mathrm{meq} / \mathrm{l}$, reduzindo a área foliar unitária em média $60 \%$, em relação à testemunha, e que as reduções de área foliar total foram mais acentuadas, sobretudo nos tratamentos com 25 e 40 meq/l (variando entre 74 e $85 \%$ em relação à testemunha) e foi atribuída a morte exagerada de folhas nos tratamentos a partir de $25 \mathrm{meq} / \mathrm{l}$, causada por necroses, principalmente, em plantas irrigadas com águas bicarbonatadas.

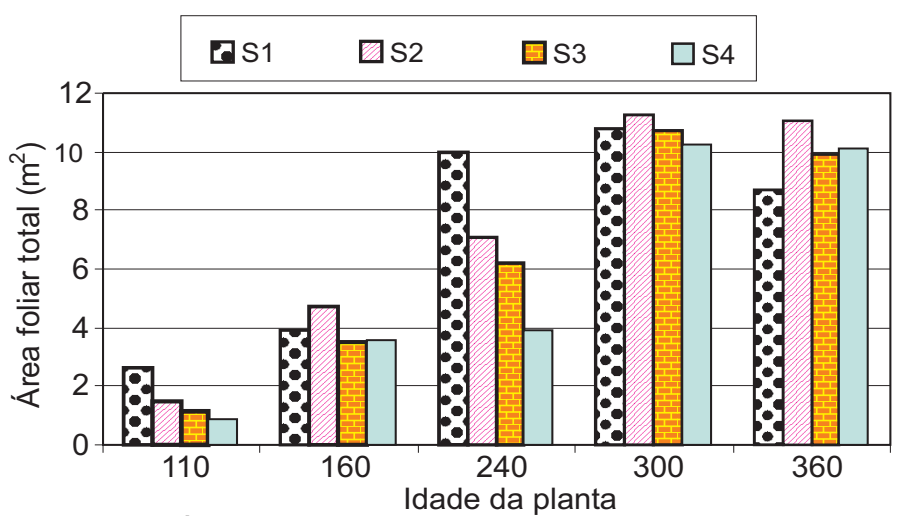

FIGURA 6 - Área foliar total por planta de bananeira ao longo do ciclo para diferentes níveis de salinidade da água de irrigação, em Mossoró, RN.
TABELA 5 -Equações de regressão e coeficiente de determinação para área foliar total por planta em função do nível de salinidade da água de irrigação, para diferentes épocas.

\begin{tabular}{ccc}
\hline Idade da planta & Equação & $\mathrm{r}^{2}$ \\
\hline 110 dias & $\mathrm{Y}=-0,49 \mathrm{x}+2,63$ & 0,88 \\
240 dias & $\mathrm{Y}=-1,64 \mathrm{x}+10,53$ & 0,96 \\
\hline
\end{tabular}

\section{CONCLUSÕES}

O crescimento das bananeiras Pacovan e Marmelo foi afetado significativamente pelos níveis de salinidade, verificando-se reduções nas variáveis estudadas (altura, diâmetro do pseudocaule e área foliar) até 240 dias; a cultivar de bananeira Marmelo apresentou parâmetros de crescimento superiores a cultivar Pacovan apenas no início, se equiparando a partir de 160 dias; as cultivares responderam igualmente à salinidade.

\section{REFERÊNCIAS BIBLIOGRÁFICAS}

AGRIANUAL 2000 - Anuário da Agricultura Brasileira. São Paulo: FNP - Consultoria \& Comércio, 2001. 435p.

ALLEN, R.G; SMITH, M.; PEREIRA, L.S.; PRUIT, W.O. Proposed revision to the FAO procedure for estimating crop water requirements. In: INTERNATIONAL SYMPOSIUM ON IRRIGATION OF HORTICULTURALCROPS, 2., 1996, Chania. Proceedings... Leuven, ISHS, 1996. v. 1, p. 17-33

ARAÚJO FILHO, J.B. de. Efeitos de diferentes níveis de salinidade de solo na composição química da folha e crescimento de cultivares de bananeira (Musa sp.) 1990. 87f. Dissertação (Mestrado). Centro de Ciências de Tecnologia. Universidade Federal da Paraíba, Campina Grande-PB, 1990.

AYERS, R. S.; WESTCOT, D. W.A qualidade da água na agricultura. Tradução de H. R. Gheyi, J. F. de Medeiros; F. A. V. Damasceno. Campina Grande: UFPB, 1991. 218p. (FAO. Estudos de Irrigação e Drenagem, 29 - revisado 1)

CARMO FILHO, F.; ESPÍNOLA SOBRINHO, J.;AMORIM,A. P. Dados meteorológicos de Mossoró (janeiro de 1898 a dezembro de 1986). 
Mossoró: ESAM/FGD, 1987.v. 341, 325p. (Coleção Mossoroense). EMBRAPA - Sistema brasileiro de classificação de solos. Brasília: Serviço de Produção de Informação, 1999. 412p.

MEDEIROS, J.F. de; GHEYI, H. R.; BATISTA, M. A. F. Procedimentos de análise de solo e água para diagnóstico de salinidade. Mossoró: ENA, ESAM, 1993. 25p. (Coleção Mossoroense, Série E, 1256)

RHOADES, J. D.; KANDIAH,A.; MASHALI, A. M. The use of saline waters for crop production. Rome: FAO, 1992. 133p. (Irrigation and
Drainage Paper, 48).

SANTOS, J.G.R. dos. Crescimento da bananeira nanica (Musa sp .) sob diferentes qualidades de água de irrigação. 1990. 78f. Dissertação (Mestrado)-Campina Grande, 1990.

SANTOS, J.GR. dos. Desenvolvimento e produção da bananeira nanica sob diferentes níveis de salinidade e lâmina de água. 1997.173f. Tese (Doutorado) - Campina Grande, 1997. 